\title{
Common Management Process Model of New TQM Based on the Situation Analysis
}

\author{
Kazuhiro Esaki \\ Faculty of Science and Engineering, HOSEI University, Tokyo, Japan \\ Email: Kees959@hotmail.com
}

How to cite this paper: Esaki, K. (2016) Common Management Process Model of New TQM Based on the Situation Analysis. Intelligent Information Management, 8, 181-193.

http://dx.doi.org/10.4236/iim.2016.86013

Received: September 5, 2016

Accepted: November 20, 2016

Published: November 23, 2016

Copyright $\odot 2016$ by author and Scientific Research Publishing Inc. This work is licensed under the Creative Commons Attribution International License (CC BY 4.0).

http://creativecommons.org/licenses/by/4.0/

\begin{abstract}
In the previous study, we suggested the concept of new TQM based on the consideration of basic concept of Quality Control. Also, in the previous study, we suggested the target domains and entities of product and process based on the TQM Matrix and view point of Three Dimensional Unification Value Models for managing quality of organization systems. Furthermore, in the previous study, we suggest the Common Management Process of organizations. Based on the above suggestion, in this paper, we would like to propose the Common Management Process Model of Total Quality Management based on the consideration of situation analysis and more precise definition of TQM Matrix and Three Dimensional Unification Value Model of "Product and Process". Improvement of quality and efficiency of organization management can be expected by the integration of conventional different management such as quality assurance, quality improvement, risk management, investment individually from the view point of common management process.
\end{abstract}

\section{Keywords}

Common Management Process Model, TQM Matrix, Three Dimensional Unification Value Model, Quality Assurance, Quality Improvement, Static Risk Management, Dynamic Risk Management, Investment Management, Project Management

\section{Introduction}

Recently, strictness of social environment of organization management is changed day by day, and company should solve many "Problems" and "Issues".

Therefore, an application of the good management process to solve these "Problems" and "Issues" are demanded from organizations. If we choose the wrong management process, it may cause a risk to produce a considerable damage in the management of organization. 
On the other hand, for a high quality evaluation of the organizational management, TQM (Total Quality Management) [1] is used all over the world and is recognized. However, it is very difficult to establish all management scope of the TQM. Furthermore, the aim of TQM must cover both "Product and Process" based on the consideration of the basic concept of Quality Control. On the other hand, we have been working on the development of ISO/IEC25000 (SQuaRE) series of standards for quality requirements and evaluation of the system and software product [2] [3] [4] [5] for a long time in ISO/IEC JTC1 (Joint Technical Committee 1 of the International Organization for Standardization and the International Electro technical Commission) SC7WG 6 (software and systems engineering). As part of this project, we have worked on the developments of ISO/IEC25030 [3], 25040 [4], 25041 [5], which are the standards to provide supporting technique of method for quantitative quality requirement definitions and evaluation of software and system product. And, quantitative quality requirement and evaluation of system are executed from the view point of system and software product quality models defined in ISO/IEC9126-1 [2] (ISO/IEC9126-1 has revised by ISO/IEC25010:2011). On the other hand, the definition of system is a combination of interacting elements organized to achieve one or more stated purposes defined in ISO/IEC15288:2008 Systems and software engineering-System life cycle processes [6]. Therefore, an organization with specific purpose is regarded as a kind of system based on the definition of system of ISO/IEC15288. Based on the above assumptions, previous study [7], we suggested the General framework of "new TQM" based on the concept of "system quality requirement and evaluation process" of ISO/IEC 25040 [4] and the original concept of "TQM Matrix" [7]. On the other hand, previous study [8], we suggested the "Three Dimensional Unification Value Model for Product evaluation based on the consideration of enlarging system product quality model in ISO/IEC9126-1 [2]. Therefore, previous study [9], we suggested the "Target Entities of Total Quality Management" for organization based on the "new TQM" and "Three Dimensional Unification Value Models". Furthermore, previous study [10], we suggested the "Common Management Process Model" based on the consideration of "TQM Matrix" and "Three Dimensional Unification Value Models". Therefore, in this article, we suggest the "Common Management Process Model" of organization based on the consideration of situation analysis as shown in Figure 5 and more precise definition of new TQM for "Product and Process [9]" as shown in Table 1. Furthermore, we report the result of confirmation of the application possibility of the "Common Management Process Model" for the four domains of "new TQM". In this paper, background of this research in clause 1, concept of new TQM in clause 2, concept of the Common Management Process Models in clause 3, verification result of the application possibility of common management process in clause 4 , conclusion described in clause 5 .

\section{Concept of New TQM}

\subsection{Basic Concept of Quality Control}

Figure 1 shows the basic concept of Quality Control that shows the relationships 
Table 1. Explanation of terminology for situation analysis.

Product

Terminology

\section{Quality:}

Whole ability of "product and process" to satisfy stated or implied needs. Objects of a quality control are quality of "product and process" usually. Quality is defined by primary quality, secondary quality and quality in use defined in ISO/IEC25000.

\section{Primary Quality:}

Quality to meet specified requirements.

\section{Secondary Quality:}

An expected quality of "Product and Process"

Fair Desire:

Desire of human kind.

Un fair Desire:

Desire of human kind.

\section{Good Cause:}

A reason that causes advantage

\section{Bad Cause:}

A reason that causes problem.

\section{Advantage:}

Good status of "Product or Process" which can achieve secondary quality.

\section{Problem:}

Abnormal status of "Product or Process" which cannot achieve primary quality. It can be finally zero if push forward to correction.

\section{Issue:}

An expected status of "Product or Process" which can achieve primary quality but cannot secondary quality. It is never disappears.

\section{Positive Risk:}

Outbreak probability and scale of expected good value. Dynamic risk management is synonyms as investment management.

Negative Risk: Outbreak probability and the scale of damage.

\section{Expected Good Value:}

An expected status of "Product or Process". The status that cannot be second quality.

Prospective damage:
From ISO, terminology "Product Quality" is defined as "totality of characteristics of an entity that bear on its ability to satisfy stated and implied needs".

"System product quality" is defined in six characteristics in ISO/IEC9126 (ISO/IEC25010) Quality models.

A product quality meets quality requirement specification of product.

An attractive product quality to meet a tacit expectation of customer needs.

Desire concerning product that may cause good cause in future.

Desire concerning product that may cause bad cause in future.

The reason that causes an advantage by product such as benefit, advantage, profit.

The reason that causes problem of product such as a defect, fault, error, obstructs.

Good status of product that is deviated from quality requirement specification of product. -For ex, advantage of product is such as useful, attractiveness, low price, profitable, etc. An abnormal status of product that is deviated from quality requirement specification of product.

-For example, a problem of product is such as a defect, a fault, an error, an obstacle, etc. An expected status of a product which want to be improved in a more attractive quality.

It is necessary to soak a priority depending on importance and urgent degree, and to push forward improvement of product.

An expected good value that may occur in the future by an activity for the resolution of an inner or outer problem or issue of product.

The damage that may occur in future by leaving problem or issue of product

An expected status of a product which want to be invested or improved in a more attractive quality. It is necessary to soak a priority depending on importance and urgent degree.

Prospective Damage of product in future.

\section{Process}

Conversion process from Input resources into Outcomes. Process is a procedure or method of the activities.

"Process quality" is the efficiency of conversion process from input resources into outcomes and that is evaluated by following equation.

Process Quality = Quality of outcomes re-sources/Quality of input resources

For example, process quality can be assured from the view points as follows.

-does PDC cycle rotate?

- to satisfy ISO 9000 requirements?

A process quality meets quality requirement specification of process. For ex, rules of inner corporation or international standard.

An effective process quality to meet a tacit expectation of stakeholders needs.

Desire concerning process that may cause good cause in future.

Desire concerning process that may cause bad cause in future.

The reason that causes advantage by process such as a quality improvement, cost down, decrease delivery time.

The reason that causes a problem of process such as a quality decline, excess over the cost, an appointed date of delivery delay.

Good status of process that is deviated from quality requirement of process.

For ex, advantage of process such as performance, cost effectiveness, etc.

An abnormal status of process that is deviated from quality requirement of process.

- For example, it is not to meet the process requirements of ISO 9000 or rules of the inner or outer organization.

Prospective quality of process that want to be improved more efficiently.

It is necessary to soak a priority depending on importance and urgent degree, and to push forward improvement of process.

An expected good value that may occur in the future by an activity for the resolution of an inner or outer problem or issue of process.

The damage that may occur in future by leaving an inner or outer problem or issue of process.

Expected quality of process which wants to be invested or improved more efficiently.

It is necessary to soak a priority depending on importance and urgent degree.

Prospective Damage of process in future. 


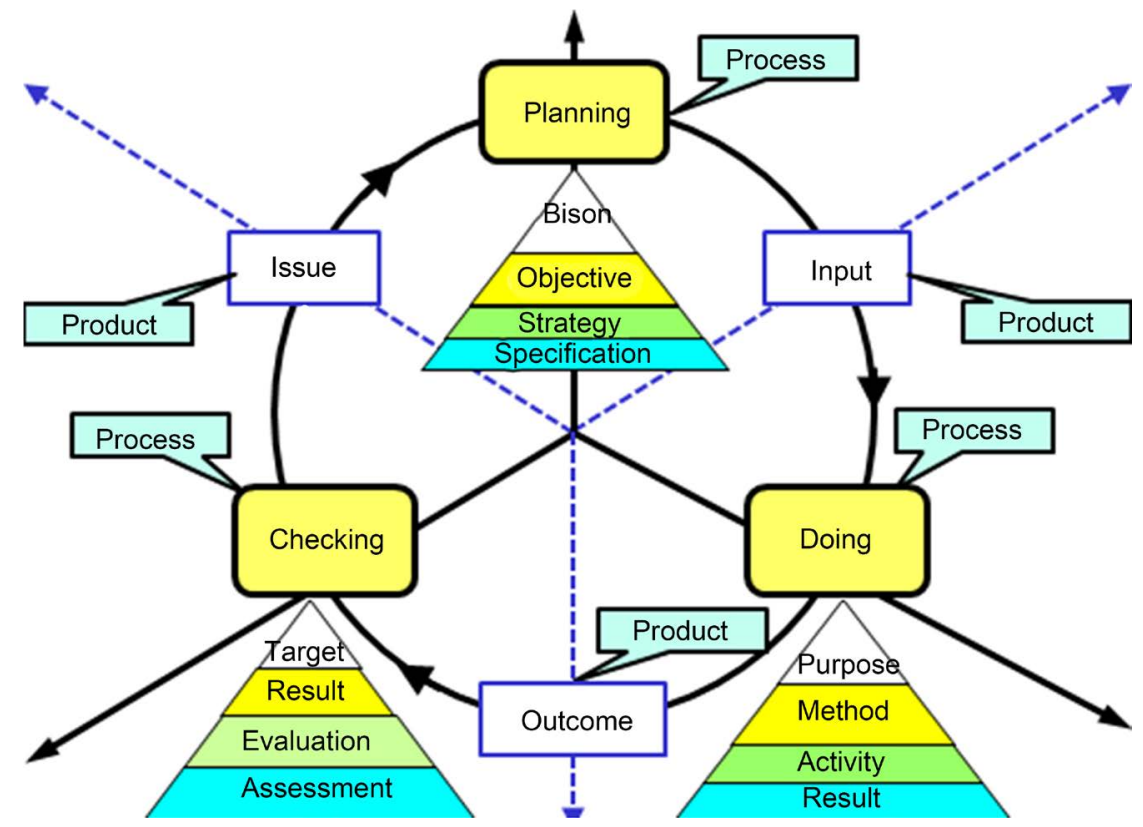

Figure 1. Basic concept of quality control [7].

between "Product" and "Process", and concept of the "CPD (Check, Plan, Do)" cycle.

From Figure 1, every kind of activities includes the "Product and Process" based on the consideration of basic concept of Quality Control. And, for the purpose of improvement of quality management, rotation of "CPD" cycle is necessary. Quality control activity is the repetition of "Product and Process", which include a sequence of "Product-Process-Product-Process and Product" during a PDC (Plan, Do, Check) cycles as shown in Figure 1. All kind of management process is affected by an Input quality of own process, which is a result of previous management process. And, the quality of process depends on a quality of previous process, and not to be able to exist alone each. In addition, consideration of "Input and Outcomes" of the process should be included in activity of organizations. Therefore, for the purpose of improvement of quality of process, it is important to evaluate not only process but also product such as "Input, Resources, Constrain and Outcomes". In order to turn a "CPD" cycle, quality of target entities about "Product and Process" should be visualized. And it is important to evaluate target entities of "Product and Process", and confirm the existence of "Problems". Generally, "CPD" is called "PDCA" cycle as "Plan-Do-Check-Action". But, improvement action is synonyms "doing" and planning is necessary before performing improvement activity. It may not be the solution of "Problem" to move to improvement without passing through the planning after checking immediately. Therefore, improvement action should be performed after planning, and resolve the confirmed "Problems". It may cause the risk that not only fail achievement of improvement but also lead the change of worse if we do not make plan before "Action" for improvement. Therefore, it is thought that you should say "PDC" instead of said "PDCA" till now. However, it is very difficult and risky to draw an ideal plan from at first. Therefore, in this study, we have used "CPD" instead of "PDCA" because it is better to check a situa- 
tion of "Issue" before planning for the purpose of improvement action. Above assumptions, we cannot evaluate the quality of process even if we measure the characteristic of process own. It is necessary to evaluate both quality of "Product and Process" based on the consideration of quality management. Every kind of activity is a process to convert from an Input product into an Outcomes product. Therefore, it is thought that the process quality can be evaluated by the quality of both Outcomes and Input. In order to improve "Outcomes", we should improve both quality of "Input Resources and Process". Table 1 is the definition and explanation of the quality-related terminologies which we showed in this paper.

\subsection{TQM Matrix}

Figure 2 shows the "TQM Matrix" which has proposed by our previous paper [7] and four target domains of "new TQM" has suggested.

From Figure 2, it is recognized that the both conventional "Quality Assurance" and "Quality Improvement" is included in the management domains of "TQM Matrix". Also, it is recognized that the additional management domains such as the "Dynamic Risk Management" and "Static risk management" are included as shown in Figure 2. The "Dynamic Risk" is defined as the scale of the "Expected Good Value" and probability that "Expected Good Value" will achieve in future when occurred. "Dynamic Risk management" should be performed based on the consideration of the view point of effectiveness, priority and limited Input Resources. On the other hand, "Static Risk" is defined as the scale of the prospected damage and probability that damage will produce in future when occurred. "Static Risk management" such as "reception, imputation, reduction and evasion" should be performed corresponding to the result of risk analysis of “TQM Matrix".

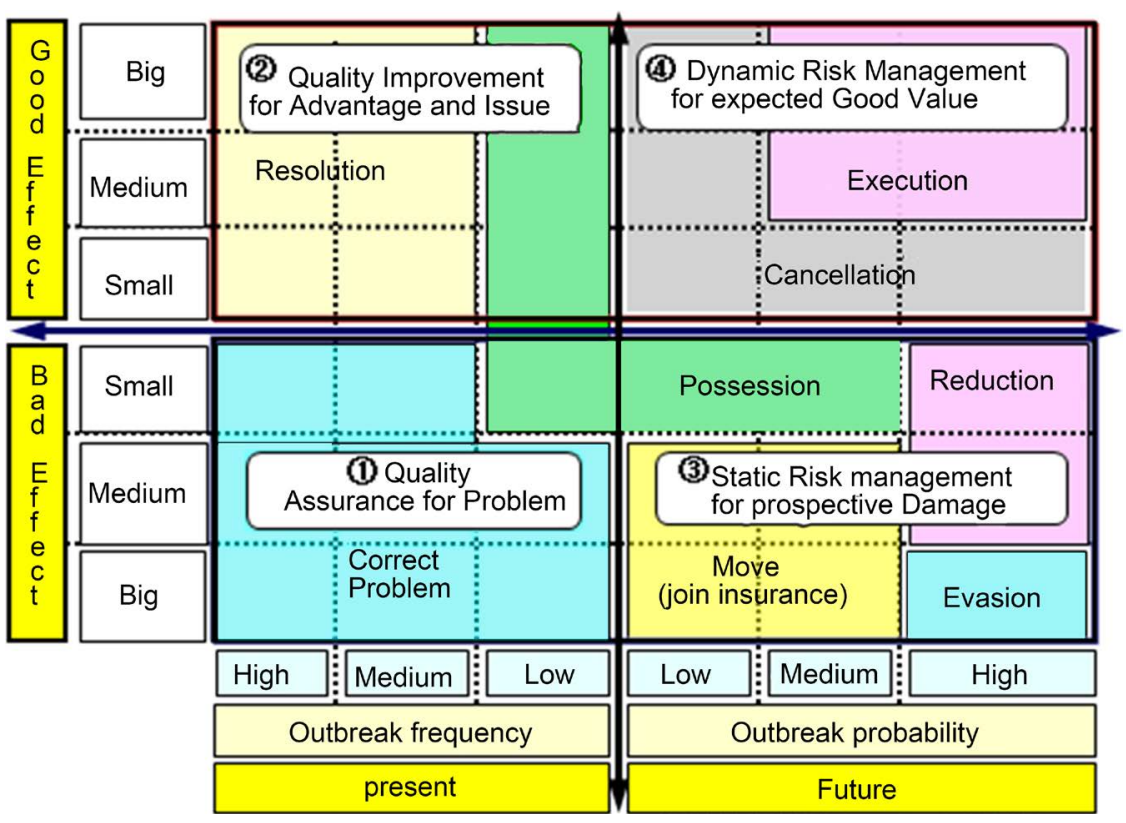

Figure 2. Concept of TQM matrix [7]. 


\subsection{Framework of New TQM}

In the previous study [7], we have proposed the framework of "new TQM" that is necessary to lead an organization for success of improvement of management quality as shown in Figure 3.

The framework of "new TQM" has defined based on the consideration of quality requirement and evaluation process of system product quality defined in ISO/IEC25040, 25041 [4] [5] and proposed concept of "TQM Matrix" as shown in Figure 2.

\subsubsection{Five Target Domain of Product}

From Figure 3, five kinds of target domains of product assessment such as Top management, Input, Outcomes, Constrain and Resources are defined in the framework of "new TQM". And, target entities of product assessment should correspond to the each target domains of product assessment.

1) Top management

This domain is located in the centre of Figure 3. Good sense of values, Public spirit, Intelligence, Decision making, Strategic planning and control, good sense of responsibility, Ability for self-act, Leadership, Communication, Fairness, Outlook on ethic, Accountability, etc.

2) Input

Necessary Resources should be taken from outside of organization or project in order to achieve purpose of activities. For example, human Resources, facilities, materials, engineering, technique, etc.

3) Outcomes

Primary results of organization activities such as "products, service and improvement". Secondary result of organization activities such as "result of various improvements or "Bad Effect" such as environmental load".

4) Constrains

It is the limitation of activities such as the "purpose, requirement, budgets and time

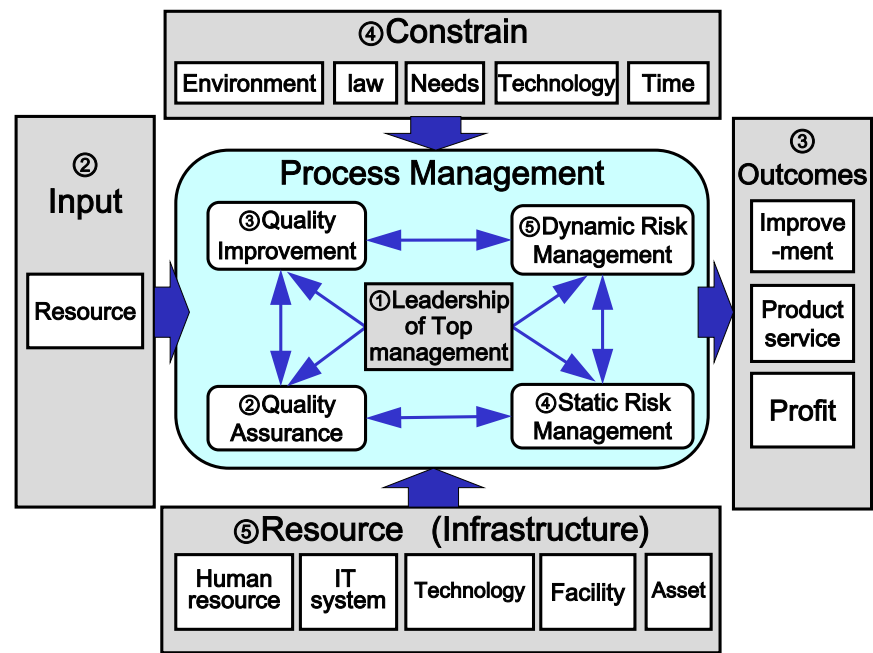

Figure 3. Framework of new TQM [7]. 
from the agreement with outside or inside stakeholders. Also, include the limitation of activities such as "law, rule, standard, corporate strategy of the organization, financial Resources, human Resources, facilities environment and technologies, etc.

5) Resources

It is the Resources or infrastructures which is the organization helping practice of the organization activity holds. For example, infrastructure for supporting organization activities such as top management, various human Resources, core technologies, information system, financial Resources, facilities, materials, etc.

\subsubsection{Four Target Domain of Process}

From Figure 3, four target domains of process assessment such as the Quality Assurance, Quality Improvement, Static Risk Management and Dynamic Risk Management (For ex, investment project management) are defined in the framework of "new TQM".

1) Quality Assurance

Activities of assurance to realize a "Primary Quality" of "Product or Process" those are specified and promised according to the contract of customers.

2) Quality Improvement

Activities of improvement for realize a "Secondary Quality" of "Product or Process". A domain of activity of improvement of "Advantage" and "Issue" of "Product or Process", and raise it to attractive quality. An "Issue" and "Advantage" does not produce the "Bad Effect" at present, but may cause "Expected Good Value" if we can improve it. It is necessary to consider a priority based on significance.

3) Static Risk Management

This domain is called "Risk Management" conventionally, however, in this paper; it is called "Static Risk Management". The "Negative Risk" may cause future "Prospective Damage" by the influenced from "Problems" or "Issues" of "Product or Process" at present in future. "Negative Risk" may cause outbreak of "Prospective Damage" in future if we ignore a "Problem" without hitting any solutions. We investigate the "Negative Risk" of "Product and Process" based on a result of risk analysis and perform "reception, imputation, reduction and evasion" as shown in Figure 2.

4) Dynamic Risk Management (Investment)

"Dynamic Risk Management" is performed in order to take "Expected Good Value" in future. Therefore, this domain is synonyms as investment management or Project risk management [11]. The "Positive Risk" may cause "Expected Good Value" by an influenced from improvement of "Advantage" and "Issue" of "Product or Process" at the present. "Positive Risk" is defined by the "probability and scale" of "Expected Good Value" or "Prospective Damage" when performing "Dynamic Risk Management".

\subsection{Three Dimensional Unification Value Model}

Figure 4 shows the concept of "Three Dimensional Unification Value Model for the management quality of process" from the consideration of basic "Concept of "Quality Control" as shown in Figure 1 and "Three Dimensional Unification Value Model of product [8]". 


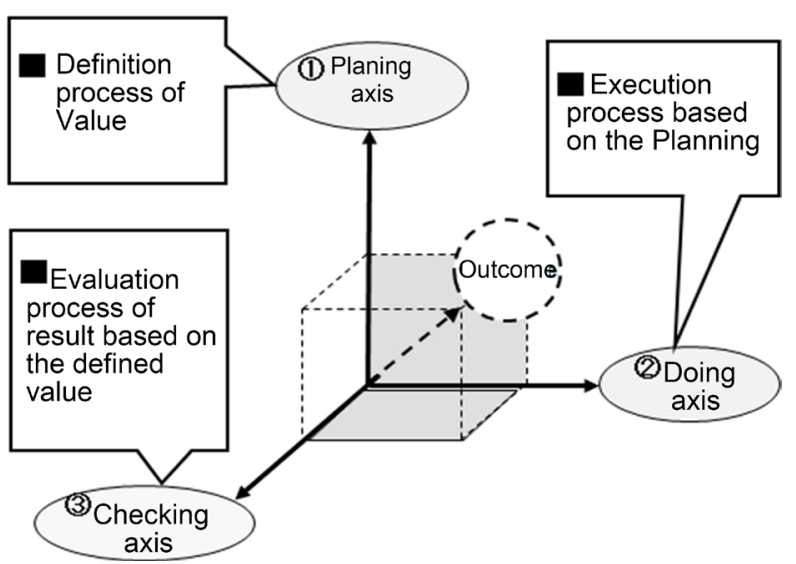

Figure 4. Concept of three dimensional unification value model for process [9].

In this model, three kinds of target entities of management process such as "Planning, Doing and Checking" are defined for the process quality assessment of organizations. These three axes are corresponds to the process of "CPD" cycle shown in Figure 1. Also, these three kinds of viewpoint correspond to the three axes of process as shown in Figure 4 and are correspond to the three characteristics of system product such as the "Value, Performance and Adaptability" for the assessment of product quality management of organizations as shown in previous paper [9].

1) Planning axis

Planning process is that defining suitable targeted values. Planning axis is the quality of planning process in order to make suitable plan that can achieve ultimate goral such as purpose, target, schedule and budget.

2) Doing axis (Execution)

Execution process is that achieve defined plan.

Doing axis is the quality of execution process to achieve targets of defined plan.

3) Checking axis (Evaluation)

Checking axis is the quality of evaluation process to take suitable result from evaluation based on the defined plan. From Figure 4, total quality of management process of organization can be unified by volume of the cuboids or vector by using "Planning, Doing and Checking axes".

\section{Common Management Process}

\subsection{Concept of Situation Analysis}

Figure 5 shows the concept of "situation analysis of quality is suggested by this paper.

The horizontal axis shows the present and the future in time axis, and vertical axis show the volume of "Good Effect" or "Bad Effect".

As shown in Figure 5, the "Good Cause" may be caused by the "Fair Desire" of past, and may cause the "Advantage" or "Positive Risk". Furthermore, the "Advantage" and "Issue" have a possibility of causing "Expected Good Value" in future. In order to identify the "Advantage" and "Issue", we should investigate the desire of interested 


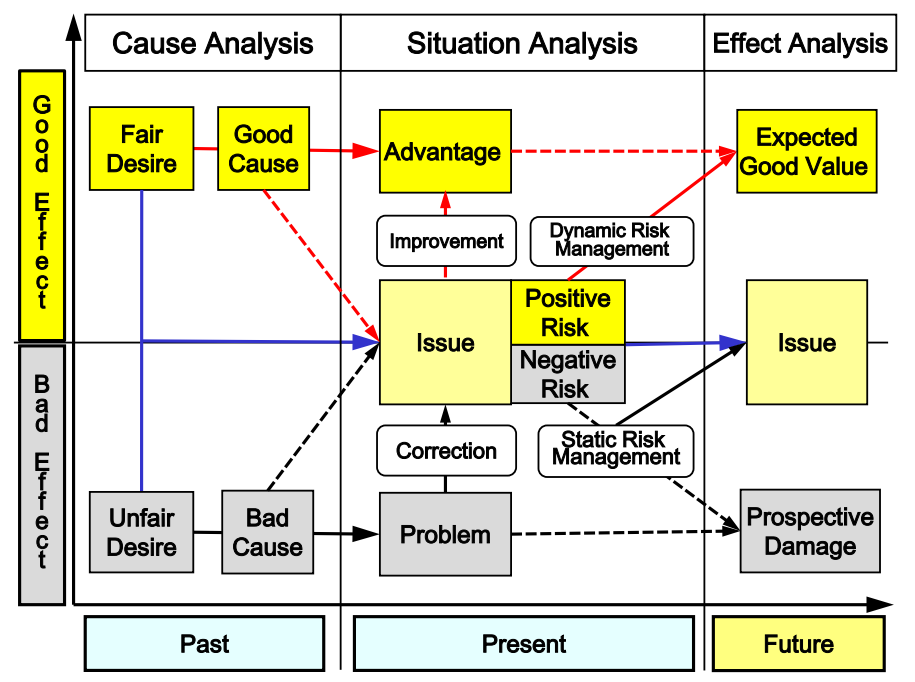

Figure 5. Concept of situation analysis.

stakeholders and should confirm the requirement of "Secondary Quality" from the needs. The "Positive Risk" is the "Issue" that the "Good Value" can be expected in future if we solve the "Issues". In order to identify a "Positive Risk", we should confirm the possibility of future "Expected Good Value" based on the situation of "Product or Process". On the other hand, the "Bad Cause" may be caused by the "Unfair Desire" of past, and may cause a "Problem" or "Negative Risk". The "Problem" may cause more serious "Prospective Damage" in future. In order to identify the "Problem", we should confirm the requirement of "Primary Quality" from the needs of "Product or Process". The "Negative Risk" is the "Issue" that the "Prospective Damage" can be predicted in future if we don't solve them. In order to identify the "Negative Risk", we should confirm the possibility of "prospective damage" based on the situation of "Product or Process". From Figure 5, we should make measures to remove the "Bad cause" of "Problem or Negative Risk" or to strengthen the "Good Cause" of "Advantage, Issue or Positive Risk" causing situation. If we carry out the solution and correct, "Problem" can be finally zero because the "Problems" are limited. On the other hand, "Issue and Risk" cannot be zero forever because the desire of interested stakeholders exists forever.

\subsection{Common Management Process Model}

Table 2 shows the target entities of total quality management processes based on the "Three Dimensional Unification Value Model for Process" as shown in Figure 4. Figure 6 shows the suggested "Common Management Process Model" based on the consideration of concept of situation analysis shown in Figure 5. Following are the detail explanation of each processes defined in "Common Management Process Model" as shown in Figure 6.

1) Information Gathering

For the purpose, at first, we should collect the concerning information about purpose.

2) Situation Analysis 
Table 2. Target entities of total management for process [9].

\begin{tabular}{|c|c|c|c|c|c|c|c|}
\hline \multirow{2}{*}{$\begin{array}{l}\text { Target Domain of } \\
\text { Process Management }\end{array}$} & \multicolumn{3}{|c|}{ 3DUVM } & \multicolumn{4}{|c|}{$\begin{array}{l}\text { Target entities of Quality Assessment for Domain of Process } \\
\text { Management }\end{array}$} \\
\hline & $\mathbf{P}$ & $\mathrm{D}$ & $\mathrm{C}$ & & P: Planning & D: Doing & C: Checking \\
\hline $\begin{array}{l}\text { Quality Assurance } \\
\text { Quality } \\
\text { Improvement, } \\
\text { Static or Dynamic } \\
\text { Risk }\end{array}$ & $\bullet$ & $\bullet$ & • & $\begin{array}{l}\text { (1) } \\
\text { (2) }\end{array}$ & $\begin{array}{l}\text { Quality of Plann } \\
\text { organization } \\
\text { Quality of Execu } \\
\text { organization } \\
\text { Quality of Evalu } \\
\text { organization }\end{array}$ & $\begin{array}{l}\text { process for } 1 \\
\text { process for } \\
\text { process for }\end{array}$ & $\begin{array}{l}\text { agement of } \\
\text { nagement of } \\
\text { nagement of }\end{array}$ \\
\hline
\end{tabular}

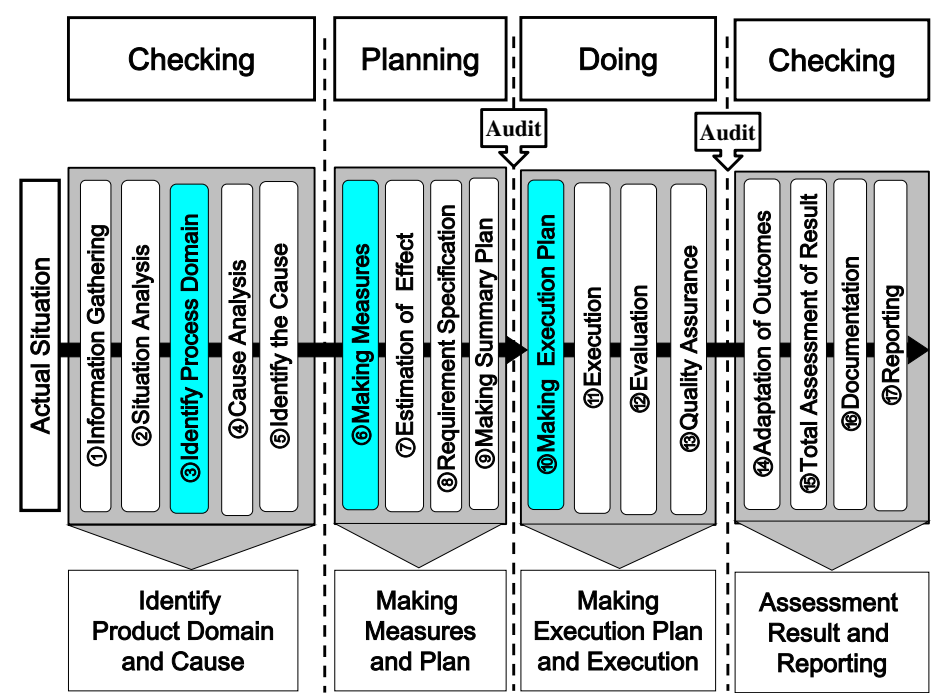

Figure 6. Common management process model [10].

In order to confirm the situation, we should investigate the interested party and the situation of "Product or Process" such as "Advantage", "Issue", "Problem", "Positive Risk" and "Negative Risk" as shown in Figure 5.

The "Issue" and "Positive Risk" is the phenomenon that leads to the outbreak of "Expected Good Value" in the future when you perform the improvement or investment. On the other hand, "Problem" and "Negative Risk" is the phenomenon that leads to the outbreak of "Prospective Damage" when you remain the "Problem" or "Negative Risk" instead of correction. If you misunderstand the "Problem" instead of "Issue", you may waste valuable financial Resources and time on the theme of small priority and may cause a loss of opportunity.

An important thing is that the later solutions and measures are different among the each domain of process management of TQM Matrix as shown in Figure 2.

Therefore, it is extremely important to identify the "Advantage", "Issue", "Problem", "Positive Risk" and "Negative Risk" accurately.

3) Identify Process Domain

After situation analysis, we should identify the four target domain of process such as "Quality Assurance”, "Quality Improvement", “Static Risk Management” and "Dynamic Risk Management". 


\section{4) Cause analysis}

If you could identify the situation such as the "Problem", "Advantage", "Issue", "Positive Risk" and "Negative Risk", you should confirm the "Cause" next.

5) Identify the Cause

If you could confirm the "Cause", you must identify the "Main Cause" of causing. Measure is the activity which to remove or strengthen the identified "Main Cause" of situation. If you identified the wrong "Main Cause", measures to remove the "Cause" become invalid and may not be connected for the solution of identified process.

6) Making Measures

After identify the "Main Cause", you must make the measures to remove the "Main Cause". The measures should be performed by the priority based on the consideration of "Urgent degree" and "Cost-effectiveness".

Usually, "Problems" should correct it immediately because they are producing a damage by the deviation from a normal state. It is necessary to carry out the measures correspond to the priority based on the consideration of emergency, importance, cost-effectiveness in the condition of limited management Resources.

7) Estimation of effect

After making Measures, you should estimate the feasibility and effect of measures.

8) Requirement Specification

After confirmation of feasibility of measures, we should define the targets of requirements.

9) Making Summary Plan

After confirmation of targets of requirements, we should make the summary plan for the purpose of audit.

10) Making Execution Plan

After audit of Summary Plan, we should make the Execution Plan which include the element such as the targets, schedule, human Resources and budget, etc.

11) Execution-Evaluation-Assessment

After audit of Execution Plan, we can execute and evaluate based on the Execution Plan shown in Figure 6.

\section{Verification of Common Process}

In this clause, result of verification of application possibility of the "Common Management Process Model" to four management domains of TQM is described. Table 3 shows the result of the applications of "Common Management Process Model" for four target domains of "TQM Matrix" based on the view point from the three target entities of process assessment of "Three Dimensional Unification Value Model". The matrix structure of Table 3 is constructed by the "four target domain of management process of TQM Matrix" as for rank and "three target entities of process assessment of Three Dimensional Unification Value Model for Process" as for column. Table 3 shows the concrete activity of each column correspond to the "Common Management Process Model" defined in Figure 6 for four target domain of management process. From 
Table 3, the common activities except target entities of process such as the "Identify Process Domain, Making Measures and Making Execution Plan" for four domain of management process are recognized. On the other hand, the differences of process in column for each four target domain are recognized. Difference between the processes is differences of the time in horizontal axis and effect of vertical axis defined in TQM Matrix as shown in Figure 2. Also, difference between concrete activities in the column for four target domains are only differences of the content of purpose and an aim. Therefore, it is thought that the "Common Management Process Model" can be applied to each domain of management process if you distinguish the target domain of process appropriately.

Table 3. Application of Common Management Process Model of New TQM based on the Situation Analysis [10].

\begin{tabular}{|c|c|c|c|c|c|}
\hline \multicolumn{2}{|c|}{$\begin{array}{c}\text { Target entities of process } \\
\text { domain }\end{array}$} & \multicolumn{4}{|c|}{ Target Domain of management Process based on the TQM Matrix } \\
\hline $3 \mathrm{D}$ & Common Process & $\begin{array}{l}\text { Quality } \\
\text { Assurance }\end{array}$ & $\begin{array}{c}\text { Quality } \\
\text { Improvement }\end{array}$ & $\begin{array}{c}\text { Static Risk } \\
\text { Management }\end{array}$ & $\begin{array}{l}\text { Dynamic Risk } \\
\text { Management }\end{array}$ \\
\hline \multirow{5}{*}{ Check } & $\begin{array}{l}\text { (1)Information } \\
\text { Gathering }\end{array}$ & \multicolumn{4}{|c|}{ Collect to necessary information for a purpose } \\
\hline & (2)Situation Analysis & \multicolumn{4}{|c|}{ Analysis of current situation based on an Organization } \\
\hline & $\begin{array}{l}\text { (3)Identify Process } \\
\text { Domain }\end{array}$ & Problem & $\begin{array}{l}\text { Advantage \& } \\
\text { Issue }\end{array}$ & Negative Risk & Positive Risk \\
\hline & (4)Cause Analysis & \multicolumn{4}{|c|}{ Cause Analysis and Assessment of current Organization } \\
\hline & (5)Identify the Cause & \multicolumn{4}{|c|}{$\begin{array}{c}\text { Identify the most important Cause concerning the issue of } \\
\text { Organization }\end{array}$} \\
\hline \multirow{4}{*}{ Plan } & (6)Making Measures & Correction & Improvement & Risk Measures & Investment \\
\hline & $\begin{array}{l}\text { (7)Estimation of } \\
\text { Effect }\end{array}$ & \multicolumn{4}{|c|}{ Fusibility study and Effort Analysis of Measures } \\
\hline & $\begin{array}{l}\text { (8)Requirement } \\
\text { Specification }\end{array}$ & \multicolumn{4}{|c|}{ Define Purpose and Targets of Measures for current Situation } \\
\hline & $\begin{array}{l}\text { (9)Making Summary } \\
\text { Plan }\end{array}$ & \multicolumn{4}{|c|}{ Define Targets, Schedule and Budget for Measures } \\
\hline \multirow{4}{*}{ Do } & $\begin{array}{l}\text { (10) Making Execution } \\
\text { Plan }\end{array}$ & Correction & Improvement & Risk measures & Investment \\
\hline & (11)Execution & \multicolumn{4}{|c|}{ Perform activities based on the execution plan } \\
\hline & (12)Evaluation & \multicolumn{4}{|c|}{ Evaluation of result of activities based on the execution plan } \\
\hline & (13)Quality Assurance & \multicolumn{4}{|c|}{ Verify and Confirm the result of execution } \\
\hline \multirow{4}{*}{ Check } & $\begin{array}{l}\text { (14) Adaptation of } \\
\text { Outcomes }\end{array}$ & \multicolumn{4}{|c|}{ Adapt a outcomes to specific context of use } \\
\hline & $\begin{array}{l}\text { (15)Total Assessment } \\
\text { of Effect }\end{array}$ & \multicolumn{4}{|c|}{ Assessment the effect of activity } \\
\hline & (16)Documentation & \multicolumn{4}{|c|}{ Make a report of result of activity } \\
\hline & (17)Reporting & \multicolumn{4}{|c|}{ Reporting and Presentation } \\
\hline
\end{tabular}




\section{Conclusions}

From the result of verification of Table 3, it is thought that the "Common Management Process Model" suggested it is applicable to each process management domain of "new TQM" instead of the conventional individual management processes such as "Quality Assurance", "Quality Improvement", "Risk Management" and "Investment Management". Furthermore, it is thought that the "PDCA" cycle of process has the "Negative Risk" for the essential solution to "Problem" and "Issue" till now.

Therefore, it is thought that it is necessary to start from Check for all management processes and should call "CPD" instead of conventional "PDCA". Improvement of quality and efficiency of organization management can be expected by the integration of conventional different management by the installation of "Common Management Process Model" suggested. In the future study, we would like to try the development of an example of application to make use of "Common Management Process Model" suggested as a future "Problem" in the unification management of the organization or system.

\section{References}

[1] American Malcolm Baldridge Prize, Criteria for Performance Excellence, 2014. http://www.nist.gov/baldrige/publications/business nonprofit criteria.cfm/

[2] ISO/IEC9126-1: Software Engineering-Product Quality-Part1: Quality Model, 2001.

[3] ISO/IEC25030: Software Engineering-Software Product Quality Requirements and Evaluation (SQuaRE)-Quality Requirement, Int'l Organization for Standardization, 2007.

[4] ISO/IEC25040: Software Engineering-System and Software Quality Requirements and Evaluation (SQuaRE)_Evaluation Process, 2011.

[5] ISO/IEC25041: Software Engineering-System and Software Quality Requirements and Evaluation (SQuaRE) - Evaluation Guide for Developers, Acquirers and Independent Evaluators, 2012.

[6] ISO/IEC15288: Systems and Software Engineering-System Life Cycle Processes-System Life Cycle Processes, Int'l Organization for Standardization, 2008.

[7] Esaki, K. (2013) General Frame Work of New TQM Based on the ISO/IEC25000 Series of Standard. Intelligent Information Management, 5, 126-135. http://dx.doi.org/10.4236/iim.2013.54013

[8] Esaki, K. (2013) Three Dimensional Integrated Value Models Based on ISO/IEC9126 System Quality Model. American Journal of Operations Research, 3, 342-349. http://dx.doi.org/10.4236/ajor.2013.33031

[9] Esaki, K. (2015) Target Entities of Total Quality Management Based on the New TQM and Three-Dimensional Unification Value Models. Intelligent Information Management, 7, 7079. http://dx.doi.org/10.4236/iim.2015.72007

[10] Esaki, K. (2015) Common Management Process Based on the TQM Matrix and Three Dimensional Unification Value Models. Handbook on Economics, Finance and Management Outlooks. 3rd International Conference on Economic, Finance and Management Outlooks, Vol. 3, 54-59.

[11] Project Management Institute (2008) A Guide to the Project Management Body of Knowledge (PMBOK Guide). 4th Edition, 14 Campus Boulevard Newtown Square, PA. 